
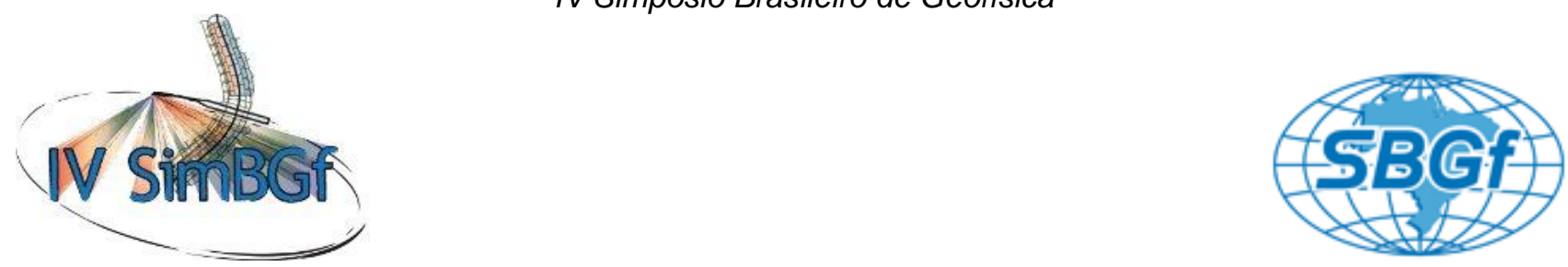

\title{
Comportamento Magnetométrico das Alcalinas do Complexo da Fazenda Buriti, Região de Iporá - GO
}

\author{
Lorena Malta Feitoza ${ }^{1}$, Adriana Chatack Carmelo ${ }^{1}$, Augusto César B. Pires ${ }^{1}$, José Oswaldo de Araújo Filho ${ }^{1}$, Roberta \\ Mary Vidotti ${ }^{1}$ \\ lorenamalta@gmail.com; carmelo@unb.br; acbpires@unb.br; oswaldo@unb.br; roberta@unb.br \\ ${ }^{1}$ Universidade de Brasília - Instituto de Geociências
}

Copyright 2010, SBGf - Sociedade Brasileira de Geofísica

Este texto foi preparado para a apresentação no IV Simpósio Brasileiro de Geofísica, Brasília, 14 a 17 de novembro de 2010. Seu conteúdo foi revisado pelo Comitê Técnico do IV SimBGf, mas não necessariamente representa a opinião da SBGf ou de seus associados. E proibida a reprodução total ou parcial deste material para propósitos comerciais sem prévia autorização da SBGf.

\section{Resumo}

As rochas alcalinas da região de Iporá (Goiás) fazem parte da Província Alcalina de Goiás e vêm sendo estudadas desde o fim da década de 60. Esta região foi afetada por importantes eventos de magmatismo alcalino durante o Cretáceo Superior, em particular, em regiões submetidas a arqueamentos crustais, condicionadas por falhamentos regionais com direção preferencial NW-SE. Estão presentes na Província complexos máficoultramáficos alcalinos, rochas alcalinas subvulcânicas e vulcânicas. O comportamento magnético identifica estas rochas devido à alta intensidade magnética existente. Desta forma, esta pesquisa fornece subsídios para um melhor entendimento da Província Alcalina de Goiás a partir da resposta magnética.

\section{Introdução}

A área de estudo está localizada na porção sudoeste do Estado de Goiás, nas proximidades de cidade de Iporá, distante cerca de $400 \mathrm{~km}$ de Brasília. Está limitada pelos paralelos $16^{\circ} 20^{\prime} \mathrm{S}$ e $16^{\circ} 25^{\prime} \mathrm{S}$ e pelos meridianos $51^{\circ} 15^{\prime} \mathrm{W}$ e $51^{\circ} 10^{\prime} \mathrm{W}$ (Figura 1).

A região está inserida na Província Alcalina de Goiás (Figura 2) que foi afetada por dois importantes eventos de tectono-magmáticos durante o Cretáceo Superior (Danni 1978). O primeiro evento está relacionado às intrusões zonadas do tipo central, caracterizadas pela série de diferenciação magmática dunitos - peridotitos piroxenitos - gabros alcalinos - nefelina sienitos. A geocronologia, pelo método em K-Ar, indica idades entre 75 e 81 Ma (Danni 1974). O segundo evento está associado à reativação dos sistemas de falhas que controlam a instalação dos corpos relacionados ao primeiro evento, sendo caracterizado por intrusões subvulcânicas, como soleiras e diques de lamprófiros, nefelinitos e analcimitos, com idades de ca. $60 \mathrm{Ma}$ (Danni 1974). As rochas alcalinas presentes na região são exclusivamente intrusivas e constituídas por dunitos, peridotitos, piroxenitos, essexitos, teralitos, gabros alcalinos, nefelina sienitos, fonólitos, traquitos, lamprófiros e produtos resultantes de processos de fenitização (Danni 1974, 1978).

Grande parte dos trabalhos que retratam a área enfoca o mapeamento, caracterização e datação destas rochas. Entretanto, poucos foram aqueles que utilizaram parâmetros geofísicos para identificar e avaliar tais rochas.

Esta pesquisa tem como principal objetivo determinar características magnéticas integrando-as com técnicas de geoprocessamento e informações geo-tectônicas, bem como contribuir para uma melhor compreensão para o mapeamento geológico-tectônico da Província Alcalina de Goiás.

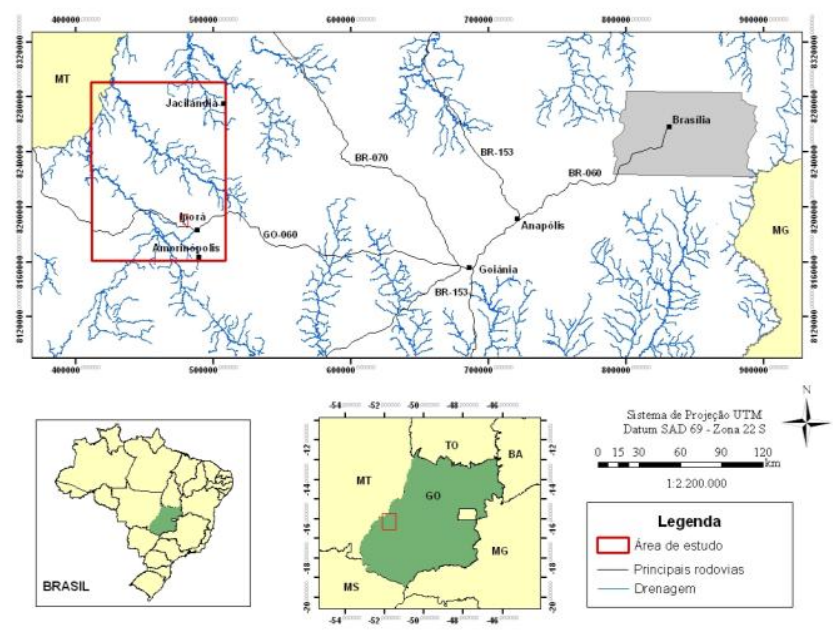

Figura 1 - Mapa de localização da área de estudo.

\section{Metodologia}

O banco de dados aerogeofísico foi adquirido a partir do convênio realizado pelo Estado de Goiás, Secretária de Indústria e Comércio e Secretaria de Geologia e Mineração - SIC/SGM, e Ministério de Minas e Energia, representado pela Secretária de Geologia e Transformação Mineral - SGM, com participação do SGB/ CPRM (CPRM 2008), cedidos ao Laboratório de Geofísica Aplicada (LGA/IG) pela CPRM. O banco de dados utilizado é referente aos dados do "Projeto do Levantamento Aerogeofísico do Estado de Goiás - $1^{\text {a }}$ Etapa: Arco de Arenópolis - Sequência Juscelândia". A aquisição dos dados magnetômetricos foi realizada em intervalos entre medições consecutivas de $0,1 \mathrm{~s}$, altura 
média de voo de $100 \mathrm{~m}$ (NS), espaçamento de $500 \mathrm{~m}$ entre as linhas de produção e de $5000 \mathrm{~m}$ entre as linhas de controle (Tabela 1).

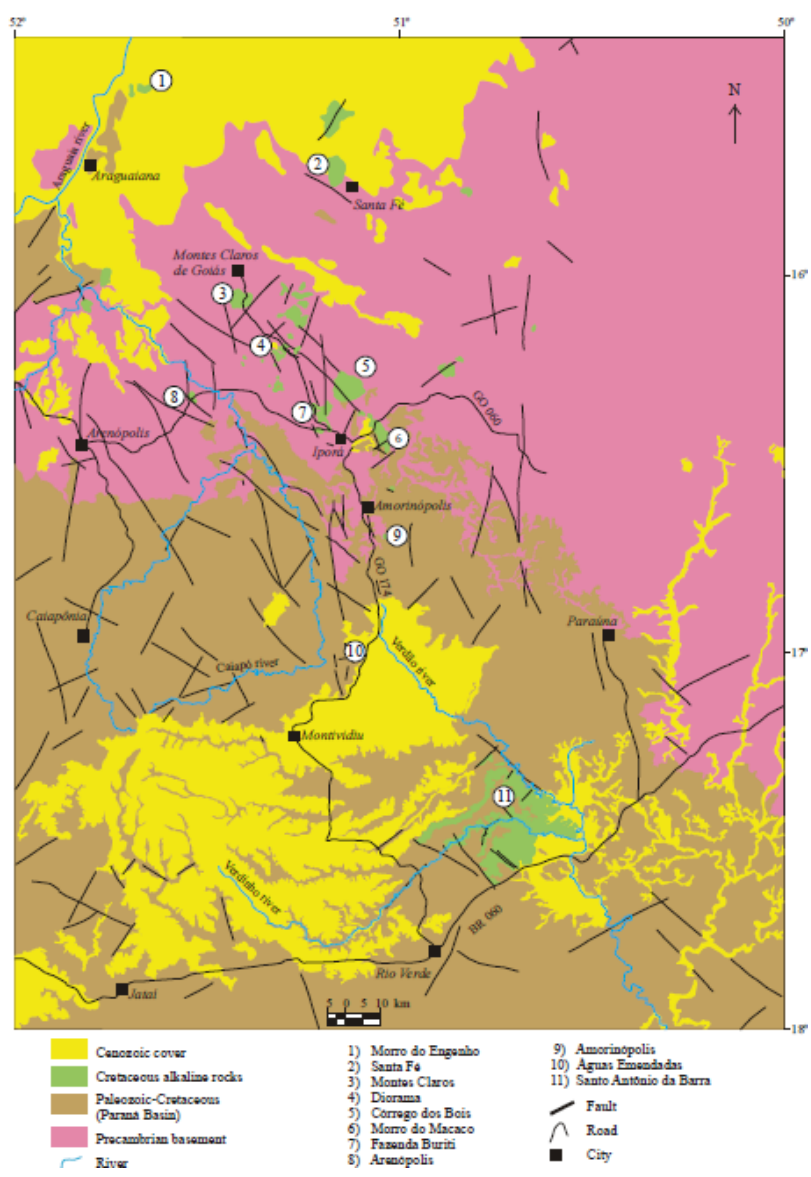

Figura 2 - Mapa geológico da Província Alcalina de Goiás, com os principais complexos plutônicos, subvulcânicos e piroclásticos. Modificado por Lacerda Filho et al. (2000).

Este Projeto tem como um dos principais objetivos oferecer suporte técnico e incentivo ao desenvolvimento do setor mineral a partir do conhecimento de propriedades geofísicas dos ambientes geológicos de Goiás.

Os dados magnetométricos indicam a somatória de respostas da intensidade do campo magnético em diferentes profundidades, próximo a profundidade Currie até a superfície. Estes dados foram processados no software Oasis Montaj ${ }^{\mathrm{TM}}$, versão 7.1.1 (Geosoft 2009). O processamento dos dados aeromagnéticos resultou da aplicação de algoritmo bidirecional que usa a distribuição dos dados orientados em linha e fortifica tendências perpendiculares às linhas de produção. Outra vantagem deste algoritmo é a contribuição na eliminação das tendências ao longo da direção das linhas de produção. O tamanho da célula unitária foi estabelecido em $100 \mathrm{~m}$. Após geração das malhas, foi aplicado micronivelamento, o que consistiu em filtragem em duas direções ortogonais, direções da linha de voo e perpendicularmente a esta (Blum 1999).
Tabela 1: Dados do levantamento aerogeofísico do Arco de Arenópolis - Seqüência Juscelândia (CPRM 2008).

\begin{tabular}{|c|c|}
\hline Projeto & $\begin{array}{l}\text { Arco de Arenópolis - } \\
\text { Sequência Juscelândia }\end{array}$ \\
\hline Código CPRM & 3009 \\
\hline Coordenadas & $\begin{array}{c}-52,50^{\circ} \text { a }-48,25^{\circ} \text { e }-14,625^{\circ} \text { a } \\
-17,75^{\circ}\end{array}$ \\
\hline Datum & SAD 69 \\
\hline Métodos & $\begin{array}{c}\text { Magnetometria e } \\
\text { Gamaespectrometria }\end{array}$ \\
\hline Contratante & $\begin{array}{c}\text { Governo do Estado de Goiás/ SIC- } \\
\text { MME/ CPRM }\end{array}$ \\
\hline Contratado & $\begin{array}{c}\text { LASA Engenharia e Prospecções } \\
\text { S.A. }\end{array}$ \\
\hline Período & $03 / 07$ a 24/ 11/ 2004 \\
\hline Total de Perfis & $135.756,53 \mathrm{~km}$ \\
\hline $\begin{array}{l}\text { Intervalo de } \\
\text { Amostragem }\end{array}$ & $\begin{array}{c}0,1 \mathrm{~s} \text { (magnetometria) e } 1,0 \mathrm{~s} \\
\text { (gamaespectrometria) }\end{array}$ \\
\hline Altura de Vôo & $100 \mathrm{~m}$ \\
\hline Área Total & $58.834 \mathrm{~km}^{2}$ \\
\hline Direção LV & $\mathrm{N}-\mathrm{S}$ \\
\hline Espaçamento LV & $0,5 \mathrm{~km}$ \\
\hline Direção LC & $E-W$ \\
\hline Espaçamento LC & $5 \mathrm{~km}$ \\
\hline $\begin{array}{l}\text { Tempo de } \\
\text { Integração Gama }\end{array}$ & $1 \mathrm{~s}$ \\
\hline Produtos & Registros digitais e fitas de vídeo \\
\hline
\end{tabular}

Para a determinação dos produtos de magnetometria, foram geradas imagens a partir do Campo Magnético Anômalo (CMA):

- Amplitude do Sinal Analítico (ASA): permite demarcar de forma mais precisa a posição horizontal das fontes causadoras do campo medido;

- Inclinação do Sinal Analítico (ISA): possibilita uma melhor demarcação das unidades físicas e das estruturas associadas;

- Continuação Ascendente (CNUP): remove ou minimiza os efeitos de fontes rasas e ruídos, consistindo de um processo que pode suprimir os efeitos de anomalias rasas, realçando detalhes gerados por anomalias profundas;

- Derivada Vertical de 1a Ordem (DZ): permite um estudo das fontes mais rasas e com isto uma melhor compreensão dos detalhes de alta frequência espacial.

Os dados do processamento magnetométrico foram uniformizados a base de dados geográficos, disponibilizada pela CPRM/SIC, a partir do Projeto Geologia do Estado de Goiás e do Distrito Federal (CPRM 2008), em escala 1:500.000, em formato digital, texto e mapas. Todo o conjunto de dados e produtos gerados foi interpretado, com intuito de relacionar a resposta magnetométrica às rochas alcalinas existentes 
na área, observando assim o comportamento magnético dessas rochas.

\section{Interpretação}

A análise do relevo referente ao campo magnético anômalo compreende o estudo dos corpos a partir dos produtos:

\section{Campo Magnético Anômalo - CMA}

A investigação da imagem CMA (Figura 3) mostra que o relevo magnético da área é caracterizado pela bipolarização magnética, apresentando alto e baixo magnético na direção NS. Nas porções norte e centro da área, o produto CMA mostra que o relevo magnético é fortemente marcado por alto magnetismo e expressivo lineamento na direção NW.

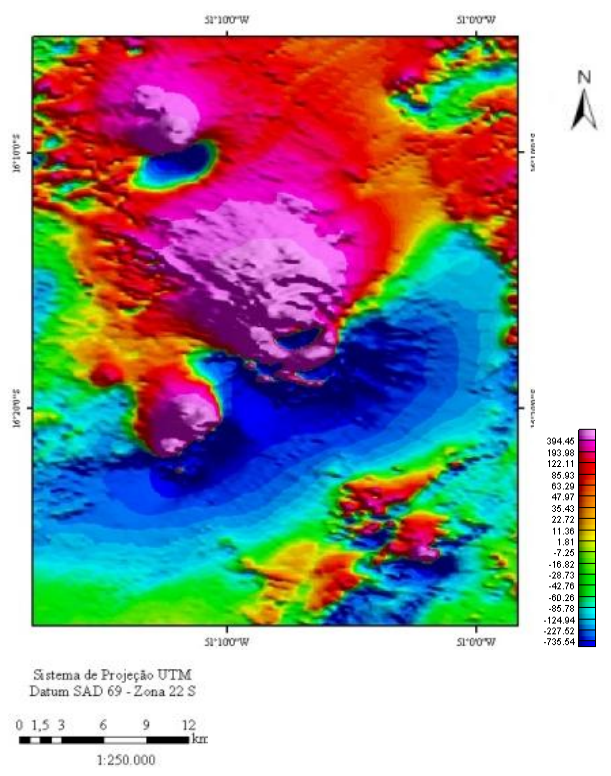

Figura 3 - Imagem do Campo Magnético Anômalo.

\section{Amplitude do Sinal Analítico - ASA}

A análise da imagem da ASA (Figura 4) do campo magnético apresenta 0 quanto 0 meio pode ser magnético, a partir da resposta das fontes magnéticas geradoras do relevo magnético, permitindo demarcar mais precisamente a posição horizontal das fontes causadoras do campo medido. A área apresenta valores altos de intensidade do campo magnético em quase toda área. $\mathrm{Na}$ porção central da área, corpos com formas circulares e altos valores de intensidade do campo magnético predominam.

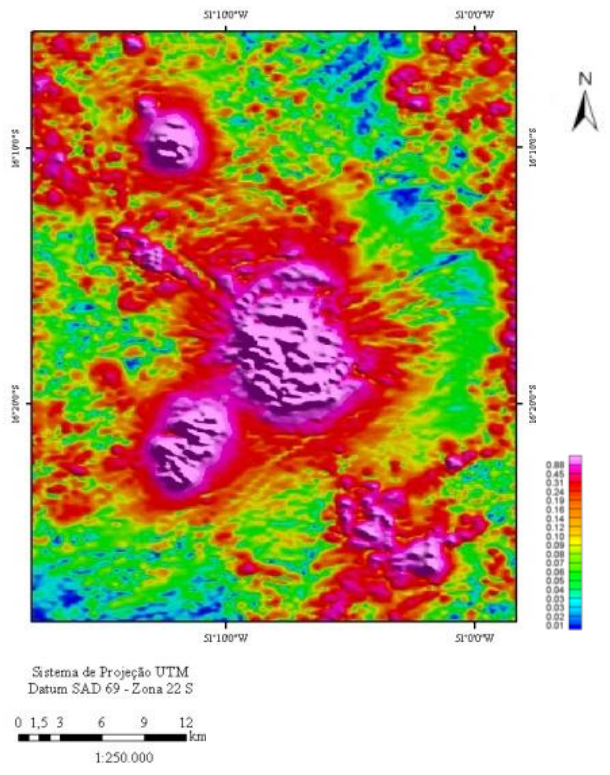

Figura 4 - Imagem da Amplitude do Sinal Analítico.

\section{Continuação Ascendente - CNUP}

A imagem CNUP (Figura 5) realça detalhes gerados por anomalias profundas. A continuação das fontes magnéticas foi analisada em quatro profundidades: 500 m, 1000 m, 1500 m e 2000 m. Essas imagens mostram bipolarizações, caracterizados por altos e baixos valores de intensidades magnéticas. $\mathrm{Na}$ área, três corpos circulares apresentam importante assinatura magnética, caracterizando alta intensidade magnética. $\mathrm{Na}$ região sudeste, em 2000 m, a assinatura magnética mostra resposta de intensidade mais baixa do campo magnético, devido à presença de fontes mais rasas.
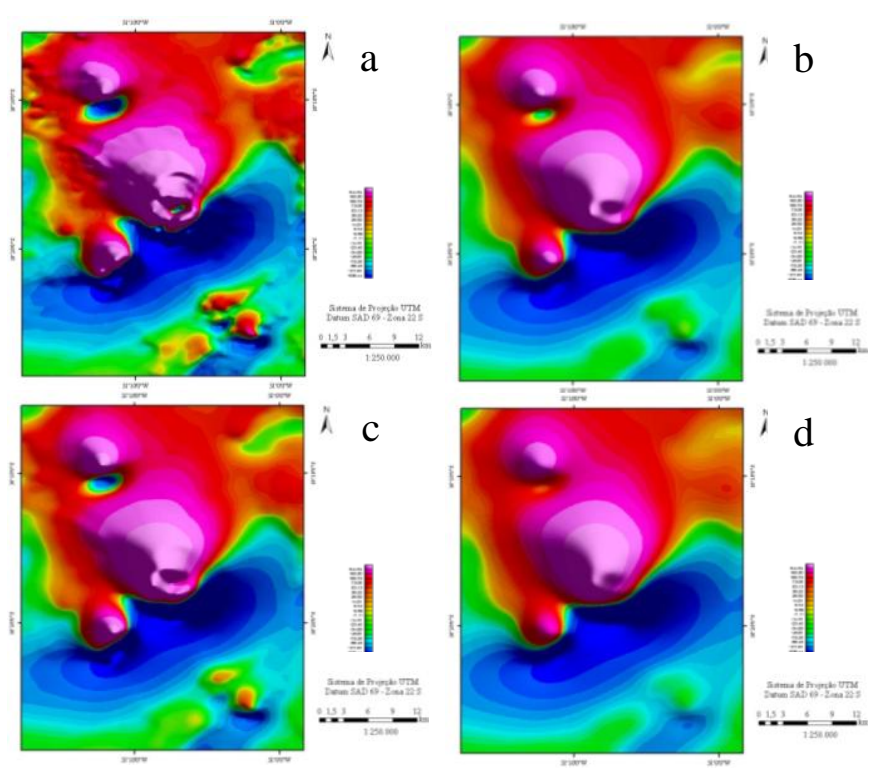

Figura 5 - Imagens da Continuação Ascendente em diferentes profundidades. (a) Profundidade de 500 m, (b) 
Profundidade de $1000 \mathrm{~m}$, (c) Profundidade de $1500 \mathrm{~m}$, (d) Profundidade de $2000 \mathrm{~m}$.

\section{Resultados e Conclusões}

Após análise e interpretação das imagens magnéticas com base na caracterização dos produtos, estas foram integradas com dados petrográficos da área (Cerqueira 1995). Figura 6.

O Diagrama $\mathrm{FeO}-\mathrm{TiO}_{2}-\mathrm{Fe}_{2} \mathrm{O}_{3}$ (Cerqueira 1995) mostra a presença de óxidos de titano-magnetita com ilmenita (Figura 6C) referentes as rochas alcalinas do Complexo Alcalino Fazenda Buriti, caracterizando o comportamento petrofísico das rochas com valores altos de intensidade do campo magnético. Este comportamento magnético pode ser associado a outras formas circulares presentes na área, caracterizando o cenário magnético da região da Província Alcalina de Goiás.
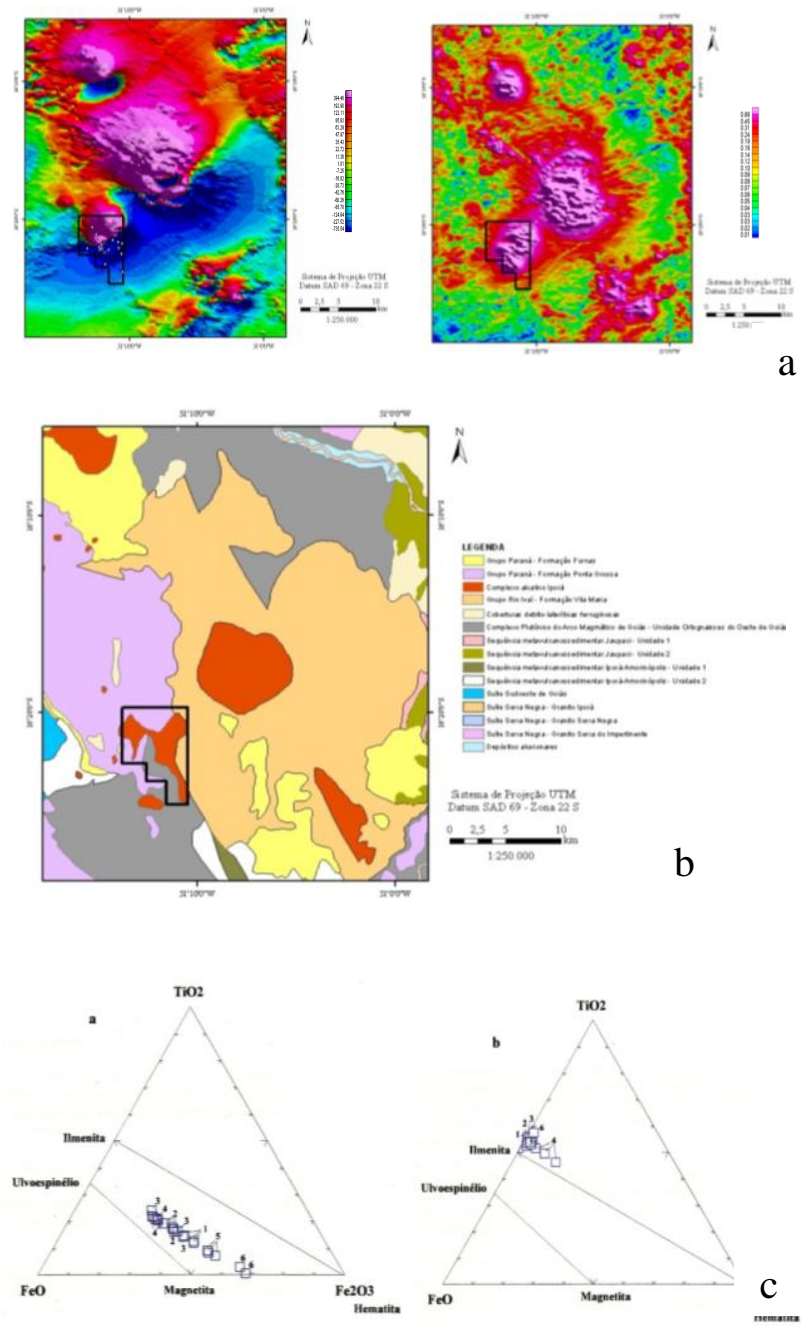

Figura 6-Características magnética (a), geológica (b) e petroquímica (c) das rochas alcalinas da porção sudoeste do estado de Goiás, região de Iporá.

\section{Agradecimentos}

Os autores agradecem a Universidade de Brasília (UnB), Instituto de Geociências (IG), Decanato de Pesquisa e Pós-Graduação (DPP) e CNPq pela infra-estrutura e apóio financeiro, e a SIC/SGM juntamente com a CPRM pela disponibilização dos dados aeromagnéticos utilizados neste trabalho.

\section{Referências}

Almeida F.F.M., Hasui Y., Neves B.B.B., Fuck R.A. 1977 Províncias estruturais brasileiras. In: SBG, Simpósio de Geologia do Nordeste, 8, Anais, p. 363-391.

Blum M.L.B. 1999. Processamento e Interpretação de Dados de Geofísica Aérea no Brasil Central e sua Aplicação à Geologia Regional e à Prospecção Mineral. Tese de Doutoramento, Instituto de Geociências, Universidade de Brasília, 229 p.

Cerqueira, M. 1995. Geologia e Evolução Petrológica do Complexo Alcalino Fazenda Buriti, Iporá-Goiás. Dissertação de Mestrado, Instituto de Geociências, Universidade de Brasília.

CPRM - COMPANHIA DE PESQUISA E RECURSOS MINERAIS. Disponível em http://www.cprm.gov.br. Acessado em 14 agosto de 2009.

Danni J.C.M. 1974. Geologie des complexes ultrabasiques alcalins de la region d'Iporà, Goiás (Bresil). Thése, Université Sud-Centre d'Orsay, Paris, 101 p.

Danni J.C.M. 1978. Magmatic differentiation of the alkaline ultrabasic intrutsions of the Iporá region, southwest Goiás, Brazil. In: International Symposium on Carbonatites, 1, p.149-167.

Fuck R.A. 1994. A Faixa Brasília e a compartimentação tectônica na Província Tocantins. In: Simpósio Geologia do Centro-Oeste, 4, Atas, p. 184-187.

GEOSOFT. 2009. OASIS Montaj - Versão 7.1.1., Inc. Toronto.

Lacerda Filho, J.V., Rezende, A. \& Silva, A. 2000. Programa Levantamentos Geológicos Básicos do Brasil. Geologia e Recursos Minerais do Estado de Goiás e do Distrito Federal. Escala 1:500000 (mapa) 2 $2^{\mathrm{a}}$ Edição. CPRM/METAGO/UnB, 184p.

SIC/ SGM - SECRETÁRIA DE INDÚSTRIA E COMÉRCIO DE ESTADO DE GOIÁS/ SUPERINTENDÊNCIA DE GEOLOGIA E MINERAÇÃO. Disponível em http://www.sic.goias.gov.br/sgm. Acessado em 03 setembro de 2009. 